\title{
Use of social media in inbound open innovation: Building capabilities for absorptive capacity
}

\author{
Ward Ooms $^{\mathrm{a}, *}$, John Bell ${ }^{\mathrm{b}, \mathrm{c}}$, and Robert A.W. Kok ${ }^{\mathrm{d}}$
}

This is a preprint of an article accepted by

Creativity and Innovation Management, 2014 @ John Wiley \& Sons, Inc.

\begin{abstract}
This study investigates the effects of the use of social media in inbound open innovation on capabilities for absorptive capacity of companies. Seven explorative case studies were conducted in an R\&D and business context of two large global high-tech companies. The results suggest that if the necessary conditions are met, social media usage increases the transparent, moderational and multi-directional interactions that in turn influence four capabilities for absorptive capacity: connectedness, socialization tactics, cross-functionality and receptivity, a hitherto overlooked capability. Hence, we observe that social media are boundary-spanning tools that can be used to build and increase companies' absorptive capacity.
\end{abstract}

\section{Keywords}

Open innovation, Absorptive capacity, Social media, Boundary-spanning tools

\section{Acknowledgements}

The authors wish to thank Lisette Appelo for her constructive and inspirational comments and her continuous support during this study.

\footnotetext{
${ }^{\mathrm{a} *}$ Faculty of Management, Science and Technology, Open University of the Netherlands (OUNL), P.O. Box 2960, 6401 DL Heerlen, The Netherlands. Tel. +31 (0) 45576 2896. Email address: ward.ooms@ou.nl.

b Philips Research, High Tech Campus 34 (5.063, 5656 AE Eindhoven, The Netherlands (j.bell@philips.com)

${ }^{\mathrm{c}}$ Tilburg School of Economics and Management, Tilburg University, P.O. Box 90153, 5000 LE Tilburg, The Netherlands

d Institute for Management Research, Radboud University Nijmegen, P.O. Box 9108, 6500 HK Nijmegen, The Netherlands (‥kok@fm.ru.nl)
} 


\section{Use of social media in inbound open innovation: Building capabilities for absorptive capacity}

\section{Introduction}

Companies need to build capabilities to develop absorptive capacity for inbound open innovation. Environmental changes require companies to recognize, assimilate and apply external knowledge - labeled absorptive capacity - in the development and production of new products (Cohen and Levinthal, 1990). Absorptive capacity affects inter-organizational learning (Lane and Lubatkin, 1998) and innovation (Fabrizio, 2009; Tsai, 2001). It not only helps to increase speed, but also the frequency and magnitude of innovation (Lane, Koka, and Pathak, 2006). While recent studies have extended external knowledge beyond R\&D to broader knowledge sources (Spithoven, Clarysse, and Knockaert, 2011; Tether, 2002), the logic is still the same: the capacity to absorb external knowledge depends upon a company’s investments in R\&D and - if it purposely wants to develop absorptive capacity - in related intra-organizational capabilities (Cohen and Levinthal, 1990; Jansen, Van den Bosch, and Volberda, 2005). For example, coordination and socialization capabilities have a positive effect on absorptive capacity (Jansen et al., 2005).

Managers may, however, lack knowledge on boundary spanning tools including social media to build such capabilities. Social media consist of a variety of online tools that enable new and easy ways of connecting with other people, for example SocialCast and LinkedIn. They are widely used for various purposes including networking, communicating, sharing, and inter- and intra-organizational sourcing (Bernoff and Li, 2008). Such boundary spanning tools might help building the necessary capabilities such as an in-house research knowledge base, the organizational coordination and the social climate.

Previous research found that internet search and communication tools positively influence R\&D efficiency (Kafouros, 2006). However, research is lacking on organizational 
mechanisms underlying inter- and intra-organizational use of boundary spanning tools. Such mechanisms are emphasized in calls for research on processes for building and maintaining absorptive capacity (Cohen and Levinthal, 1990; Lane et al., 2006) and on processes towards open innovation (Chiaroni, Chiesa, and Frattini, 2011; Huizingh, 2011). The purpose of our study is to understand the organizational mechanisms through which social media usage builds socialization capabilities (connectedness and socialization tactics) and coordination capabilities (cross-functional interaction and receptivity) that in turn develop absorptive capacity. Therefore our research question is: How does the use of social media in innovation processes affect socialization and coordination capabilities for absorptive capacity?

To answer this question, we conducted explorative multiple case research in two large global high-tech firms. The cases studied used social media as an integrated part of the innovation process for the shared purpose of obtaining relevant external knowledge at different stages. The resulting insights may improve managers' understanding of how social media develops conditions for absorptive capacity and of the risks associated with the incorporation of external knowledge. Our study contributes to research on building absorptive capacity by focusing on knowledge breadth (receptivity) as well as knowledge depth. Prior research mainly concentrated on the latter (Jansen et al., 2005), where knowledge breadth is important for purposefully developing absorptive capacity to explore new knowledge domains (Cohen and Levinthal, 1990). This study also contributes to open innovation research suggesting that companies cannot ignore the role of boundary-spanning tools such as social media. Such tools are largely overlooked in academic research that emphasizes strategies to access external knowledge (Gassmann, 2006).

The next section outlines the theoretical background. Then the methodology is discussed and the results are presented. The last section provides conclusions and discusses the 
theoretical and managerial implications as well as the limitations and future research suggestions.

\section{Theoretical Framework}

One assumption central to the open innovation framework is that useful knowledge is widely distributed (Chesbrough, 2006: p. 2). This assumption implies that any R\&D organization, independent of its size and capabilities, must try to identify useful external knowledge sources and access them to capture value in line with the company's business model. Such external knowledge exploration processes are part of an inbound - outside-in - open innovation strategy (Huizingh, 2011) and are part of the absorptive capacity (Cohen and Levinthal, 1990).

\section{Absorptive capacity}

Absorptive capacity is seen as an organizational ability to recognize, assimilate and use external knowledge that needs to be complemented with an internal $R \& D$ knowledge base (Cohen and Levinthal, 1990; Lane et al., 2006). This type of capacity is perceived to be crucial to the overall innovative capabilities of firms and, thus, their competitiveness. The ability to absorb external knowledge is dependent on the company's prior related knowledge that is the result of R\&D investments (Cohen and Levinthal, 1990). Such prior related knowledge likely leads to the development of absorptive capacity as a byproduct of the process to generate technical knowledge for new products close to the current knowledge domain. Aiming to explore new knowledge domains, the company may not solely rely on absorptive capacity developed as a byproduct of investing in $R \& D$, but should actively invest in developing related intra-organizational capabilities (Cohen and Levinthal, 1990; Verona, 1999) and inter-organizational capabilities (Dyer and Singh, 1998; Spithoven et al., 2011). This is recognized in reconceptualizations of the original concept viewing absorptive capacity 
as a dynamic capability (Zahra and George, 2002), with distinct phases (Lane et al., 2006;

Zahra and George, 2002), and adopting a process and interactive perspective (Easterby-Smith, Graça, Antonacopoulou, and Ferdinand, 2008; Marabelli and Newell, 2014).

Zahra and George (2002) distinguish potential absorptive capacity that refers to the acquisition and assimilation of external knowledge, from realized absorptive capacity that refers to transformation and exploitation of external knowledge. Both capacities are separate but necessary and complementary components of absorptive capacity to leverage external knowledge to one's benefit (Zahra and George, 2002). Different studies have tried to uncover how potential absorptive capacity and realized absorptive capacity can be optimally balanced (Jansen et al., 2005; Volberda, Foss, and Lyles, 2010; Zahra and George, 2002). The combined effect of potential and realized absorptive capacity on innovation performance is found to be greater than the effect of its components (Ebers and Maurer, 2014). Still, the empirical evidence is mixed, as Jansen et al. (2005) find that high potential absorptive capacity without complete realization, rather than maximizing the realization of potential absorptive capacity (Zahra and George, 2002), leads to increased innovation performance. Alternatively, Lane et al. (2006) characterize absorptive capacity by phases of exploratory, transformative and exploitative learning. These three learning processes correspond closely to the processes associated with the phases of potential and realized absorptive capacity.

However, recent conceptual debates highlight several weaknesses in conceptual and empirical studies on absorptive capacity and call for a process perspective (Easterby-Smith et al., 2008; Marabelli and Newell, 2014). First, the absorptive capacity literature may have fallen victim to a 'linearity trap' by conceptualizing of the process as a linear 'pipeline' or 'funnel' (Lane et al., 2006; Marabelli and Newell, 2014; Todorova and Durisin, 2007). The critics argue that, rather, the phenomenon of "knowing is a continuous performative accomplishment” (Marabelli and Newell, 2014: p. 12). Hence, the four absorptive capacity 
processes that are commonly adopted in the literature (acquisition, assimilation, transformation and exploitation) interact and should not be interpreted as subsequent isolated steps such as potential and realized absorptive capacity. The innovation management literature experienced a similar shift from a linear perspective to an evolutionary perspective (Malmberg and Maskell, 1997). Second, various studies have identified an overemphasis in absorptive capacity literature on the importance of firms’ prior knowledge bases. This narrow focus is argued to be at the expense of attention for absorptive capacity its process and policy aspects (Easterby-Smith et al., 2008; Lane et al., 2006; Marabelli and Newell, 2014). This blind spot in the literature has sparked an increased interest in issues of power, the agency of individuals in knowledge exchange and the role of boundaries in absorptive capacity processes (Marabelli and Newell, 2014). Finally, whereas quantitative methods have been predominantly used to study absorptive capacity, qualitative approaches may be better suited to capture both the interactive nature of absorptive capacity as well as its process and policy aspects (Easterby-Smith et al., 2008).

We distinguish inter-organizational from intra-organizational capabilities and focus on the latter in this study. Inter-organizational capabilities typically involve mechanisms such as collective research centers (Spithoven et al., 2011), strategic alliances and other cooperative strategies (Dyer and Singh, 1998), industrial clusters (Lazaric, Longhi, and Thomas, 2008) and social embeddedness in firm networks (Uzzi, 1997). Intra-organizational capabilities refer to mechanisms that operate within the boundaries of the company.

\section{Intra-organizational capabilities for Absorptive Capacity}

Three broad types of intra-organizational capabilities are related to absorptive capacity: coordination, socialization and change/system capabilities (Jansen et al., 2005; Van Den Bosch, Volberda, and De Boer, 1999). Change/system capabilities can alter programmed behaviors meant to create patterns of organizational actions (Galbraith, 1973) and include 
systems of routines and formalization (Jansen et al., 2005), training of personnel, attitude towards change (Murovec and Prodan, 2009), and employee attitudes such as the NotInvented-Here syndrome (Menon and Pfeffer, 2003). Coordination and socialization capabilities do not so much alter programmed behavior, but enable appropriate behavior through integrating efforts across disciplines or hierarchies and develop common understandings respectively (Henderson and Cockburn, 1994; Verona, 1999). We investigated socialization and coordination capabilities for two reasons. First, these capabilities together capture knowledge depth and knowledge breadth respectively. Knowledge depth refers to within-field knowledge whereas knowledge breadth refers to across-field knowledge (Prabhu, Chandy, and Ellis, 2005). This is similar to search depth and search scope (Katila and Ahuja, 2002) or exploitation and exploration (March, 1991). Second, compared with other capabilities, socialization and coordination capabilities most strongly and positively influence absorptive capacity (Jansen et al., 2005).

Socialization capabilities refer to the ability to develop common understandings and procedures for appropriate organizational actions. They capture knowledge depth, because developing common understandings refers to creating a shared picture of knowledge within a field. Connectedness and socialization tactics are included, because they reflect Granovetter's (1992) main distinction between structural and relational embeddedness (Jansen et al., 2005; Nahapiet and Ghoshal, 1998). Connectedness - the density of linkages between actors - is a governance mechanism for interactions and facilitates knowledge exchange (Jaworski and Kohli, 1993; Rowley, Behrens, and Krackhardt, 2000). Connectedness in boundary-spanning networks not only enhances absorptive capacity microfoundations (Lewin, Massini, and Peeters, 2011) such as sharing and transferring knowledge and practices through improving efficiency of knowledge exchange (Galunic and Rodan, 1998) and managing adaptive tension 
through reducing goals and implementation conflicts (Rindfleisch and Moorman, 2001).

Consequently, it enhances assimilation processes but also transformation and exploitation processes of absorptive capacity (Jansen et al., 2005). Socialization tactics capture the process of bonding, where individuals align their beliefs, values, and needs, and as such strengthen their relationships (Ashforth and Saks, 1996). Socialization tactics enhances microfoundations such as internal selection regimes and learning from and with partners through building trust and cooperation (Nahapiet and Ghoshal, 1998). This positively affects the transformation and exploitation processes of absorptive capacity (Jansen et al., 2005).

Coordination capabilities refer to creating unity of efforts across disciplines and hierarchies and include cross-functional interfaces, participation in decision making, and job rotation (Henderson and Cockburn, 1994; Van Den Bosch et al., 1999; Verona, 1999). We focus on cross-functional interaction and - a hitherto not included capability - receptivity, because these two capabilities - but especially the last one - best capture knowledge breadth in the sense of covering a wide range of knowledge fields. Cross-functional interaction or cooperation - defined as "the quality of tasks and interpersonal relations when different functional areas work together to accomplish organizational tasks” (Pinto and Pinto, 1990: 203) -occurs in social networks especially when managers participate and it enhances frontend ideation, development and refinement (Kijkuit and van den Ende, 2010). It enhances absorptive capacity microfoundations (Lewin et al., 2011) such as facilitating variation and sharing knowledge and practices through supporting the acquisition of wide external knowledge using various angles, but also through deepening the understanding of external knowledge and refining its interpretations. Consequently, it significantly affects the acquisition and assimilation of external knowledge as part of absorptive capacity (Jansen et al., 2005). Receptivity is defined as the ability to receive more knowledge and more diverse 
knowledge from the environment. It involves the variety and amount of the external knowledge accessible as well as the variety and amount of receptors to external knowledge, similar to what Cohen and Levinthal (1990: p.132) call "a fairly broad range of prospective “receptors” to the environment”. It enhances microfoundations of absorptive capacity such as identifying, recognizing and reflecting upon the value of externally generated knowledge. Broader environments, for examples loosely coupled networks, characterized by weak ties, are more able to come up with novel solutions (Boschma, 2005; Grabher and Stark, 1997). Exposure to a wide range of (broad) knowledge is an important determinant of absorptive capacity particularly if external knowledge is related to development activities that are subject to technological turbulence (Cohen and Levinthal, 1990; Lane et al., 2006).

\section{Social Media}

Social media are web 2.0-based applications - such as YouTube, Twitter, Facebook, Yammer, and LinkedIn - that allow for multidirectional communication and are mainly based on user generated content, which require active use to assure their continuous existence (Kaplan and Haenlein, 2010; Michelis and Schildhauer, 2010). Compared to face-to-face, email and web 1.0 contact, they are faster and more actively used for connecting larger and more diverse sets of people, and creating and maintaining interactive interest groups.

Given the lack of effect studies on social media we express our expectations about the relationships between social media and the coordination and socialization capabilities. The density of linkages between network members - connectedness - is likely to be influenced by social media. As social media enable a diverse and large set of people to connect and to create interactive interest groups that communicate multi-directionally more linkages between people are to be expected. Also, the strength of linkages and the degree of bonding socialization tactics - are larger as a variety of groups with people sharing similar interests 
are likely to arise in social media networks. This may lead to a subtle interplay of divergence and convergence of ideas and opinions.

Social media are likely to influence cross-functional interaction - a diverse set of members connecting across functional boundaries and hierarchical lines. In principle, anyone is able to exchange knowledge with any other social network member, irrespective of their function or authority. As such, social media enable the occurrence of non-routine communication lines. Social media are also likely to enlarge receptivity - that captures both the increase in receptors and its variety and the increase in knowledge and its variety. In contrast to more conventional media, social media expose a larger number and variety of people to a larger variety of external knowledge. Because they enable more flexibility and freedom of participation and are more open to participation, social media are less likely than traditional media to lead to negative effects such as loss of autonomy, social pressure to conform, and lock-in or groupthink (Kijkuit and van den Ende, 2010). Social media enable its users to filter and select guided by their own preferences and judgment.

Receptivity is expected to affect absorptive capacity. With a greater variety of individuals exposed to external knowledge, one can expect acquisition of a richer, sometimes unanticipated, body of external knowledge (Jansen et al., 2005). Kijkuit and Van den Ende (2010) show that a larger network size can lead to more ideas which is beneficial for front-end innovation. Due to social media's reach and transparency, the amount and variety of knowledge available for exploration is likely to increase. Being receptive to a larger variety of knowledge sources enhances absorptive capacity processes of assimilation and acquisition, as the knowledge one is exposed to is more likely to be novel (van de Vrande, Vanhaverbeke, and Duysters, 2011).

\section{Methodology}


To examine how social media can create conditions to develop absorptive capacity, we conducted seven explorative case studies of social media use in innovation processes at two large, global high-tech companies. For example, one case involved knowledge exploration in the fast-paced field of cognitive neuroscience, whereas another case aimed to absorb insights from professional users of medical devices. Table 1 indicates for every case the role it fulfilled within the innovation process and describes the type of social media used. In the Key case, R\&D staff (scientists, engineers, and management) participated in a real scenario of (external) knowledge exploration through a dedicated social media group. This case is a representative or typical case (Yin, 2009) that, as part of the multiple-case design, contributes to a more comprehensive understanding. In the other six cases, social media initiatives were either in progress or had just ended by the time of study. We followed a theoretical sampling strategy (Eisenhardt, 1989; Gibbert, Ruigrok, and Wicki, 2008) based on two dimensions. First, all cases can be assigned to one of two categories based on the respective context they are embedded in, namely: (1) research \& development or (2) business. Second, cases were found to involve social media usage where users were given the ability to generate content and interact with various other users. This is a distinctive property of social media as opposed to more conventional media. Hence, all of the sampled cases involved the use Web 2.0 applications including SocialCast, LinkedIn, jams, and innovation broker tools (e.g., crowdsourcing contests). To ensure internal validity the operationalization was guided by a theoretical propositions.

\section{Data Collection}

Case data were collected using multiple informant semi-structured interviews triangulated with relevant policy documents and observations from several cases. Semi-structured interviews were used to collect data because such interviews allow for theory-driven, proposition-directed questions to be asked (Flick, 2009). Interview questions were developed 
to gather descriptive data for each case as well as rich data on interviewees’ perceptions regarding conditions enabling the development of absorptive capacity. The interview guide was subdivided into part I with questions openly discussing how coordination and socialization capabilities have developed and what helps them to develop and part II with questions on what social media usage is, how it varies and how it influences these capabilities and with questions on the mechanisms and conditions under which this occurs. Separate interview guides were used for the first case and the latter 6 cases. For the latter 6 cases, questions were included to obtain a better understanding of each case its context. Multiple informants per case were selected whenever possible (see table 1), as this generally yields richer and better information and thereby improves construct validity of this study (Van Bruggen, Lilien, and Kacker, 2002).

The interviews in the first (key) case were conducted in June and July 2011 and included 10 participants as well as 10 non-participants (to capture non-participation bias). The first case ran for about 3.5 weeks (in June 2011) and was preceded by a repeated announcement by the researcher and initiative sponsor. A special interest group on cognitive neuroscience with ample room for exploration of knowledge was targeted. 106 employees linked to this group were invited to join the exploration process, 29 of them chose to participate. 12 interviews were conducted for the other 6 cases between April and June 2011. An effort was made to select interviewees from different organizational roles for each of the initiatives.

Average interview duration was 40 minutes, which proved sufficient to obtain the insights. The policy documents, such as social media guidelines and training materials, collected were used to check interview data. Observations of events, i.e. specific interactions, on social media platforms in our cases were compared with interview data.

$====$ Insert Table 1 about here $====$ 


\section{Measures}

Connectedness is measured as the density of linkages between actors in boundary-spanning networks based on Jansen et al. (2005). Jaworski \& Kohli (1993, p.59) describe density of linkages as "the extent to which individuals were networked”. For example, data referring to the number of linkages and development of new linkages was coded at this indicator. Other indicators are access and awareness: participants’ perception of access to and awareness of external (sources of) knowledge based on Galunic and Rodan (1998). For these indicators, data were coded discussing issues of one's visibility or data indicating how interviewees develop an impression of another individual's expertise. Socialization tactics are measured as the level of bonding and the strength of the linkages. Typically, this involved data showing how linkages established on social media developed in to more intensely utilized linkages, where people also meet physically or grow to feel affiliated with communities. Crossfunctionality has indicators based on Jansen et al. (2005) and Egelhoff (1991): participants' perceptions on the ability to interact across functions and their experience of hierarchical constraints or authority control. For example, data was coded referring to situations in which interaction occurred between individuals in different organizational roles. Moreover, the degree of routine and reciprocity are indicators, where cross-functional knowledge flows are characterized by low routine and high reciprocity. Receptivity is measured by the amount and variety of knowledge and of the receptors of knowledge. Indicators used are the following. People's perceptions of the variety in accessible knowledge and of the amount of accessible knowledge. This includes individual's perception of their freedom to filter and select knowledge, of transparency in decision-making, of flexibility in filtering and selection, and of the likelihood of encountering unanticipated knowledge (Jansen et al., 2005). For example, many interviewees discuss their reach to specific sources of knowledge or the degree to which 
knowledge is subject to an editorial filtering process. Transparency has implications for people’s receptivity to knowledge for decision-making and of its outcomes. Encountering unanticipated knowledge suggests an increase in variety as well as receptivity. We coded data referring to interviewees being involved in surprising, serendipitous discoveries when searching for external knowledge. These indicators are largely based on the notion that increased receptivity allows different perspectives to interactively shape rich bodies of knowledge (Hage and Aiken, 1967, p.510; Jansen et al., 2005, p.1001).

Absorptive capacity. Elements of the absorptive capacity process were measured along its dimensions. First, assimilation is measured based on participants’ perceptions of the speed, depth, and quality with which they can assess and interpret external knowledge (Jansen et al., 2005), these involve issues of common language, compatibility and complementarity (Jansen et al., 2005; Jiménez-Barrionuevo, García-Morales, and Molina, 2011). The experienced speed, depth and quality were explicitly discussed with interviewees and coded correspondingly. Second, acquisition is measured as: participants’ experience with regard to their ability to select and filter knowledge themselves, the control they perceive to have over knowledge acquisition decisions, and the extent to which they are able to create support for such decisions (Aldrich and Herker, 1977). For example, where knowledge acquisition was supported by managers, experts or the broader crowd were coded. Processes of transformation and exploitation could not be measured, because the social media initiatives in the cases were either in progress or had just ended.

\section{Data Analysis}

Interview data was carefully coded. Subsequently, data coded at each dimension were tabulated based on word frequency as to surface themes present in the data and thereby direct 
analysis, as advised in Yin (2009). Data displays were created to examine data and its implications more closely.

We applied a pattern-matching logic to analyze the interview data. This allowed empirically based patterns to be related to predictions of dependent and independent variables of the study (Yin, 2009: p. 136). 'Member checks' (Flick, 2009) were performed by means of two presentations of the preliminary findings, conclusions, and recommendations to one group of participants and non-participants from the key case and one group of management and experts. The feedback largely confirmed the interpretation of the results, thereby strengthening construct validity (Gibbert et al., 2008). Member check feedback was used to further refine the interpretation of the data.

\section{Results}

\section{Social media and connectedness}

Our data suggest that participants in communities within social media do experience increased awareness of and access to others, and thus increased density of linkages amongst network members. Most interviewees argue that awareness of the relevance of other community members as a knowledge source is of particular importance (Quote 1). Relevance may refer to the quality (degree of expertise of a member), but also to a member’s organizational role; e.g. managers vs. scientists. This is illustrated by the following quote:

\footnotetext{
"People get more aware of what others are doing. Certainly, if the person at the other end of the wire is interesting. It is all about the relevance! [...] if the person is relevant, then you will invest the time.” Quote 1 - Key Case 1 - Scientist
} 
There are also limits to the access to certain external knowledge sources, as some interviewees point out that they would be reluctant to participate in communities in which there is pressure to contribute and the level of discussion is increasingly technical. As one interviewee states:

“[...] They don’t want you to just be there and be nice, but they want you to really add something. Have a point... [...]”

Quote 2 - Key Case 1 - Scientist

Social media facilitate the availability of more relevant people (sources of knowledge) than traditional media do and enable accessing these people. Interviewees from our cases attribute this largely to the ease of participation, as social media allow for non-physical and nontemporal interaction. While this also holds for e-mail, social media offer more transparent and multidirectional interaction in ongoing issues. Transparency creates social pressure to reply, increasing not only the peer involvement but also the involvement of higher level managers. Such involvement and multidirectional interaction increases the reach of individual's social networks, enabling connections with people otherwise unavailable. Each new connection further enlarges employees’ reach to other internal or external people. Likewise, employees also experienced that they can be found and accessed more easily themselves as knowledge sources.

“With this platform [social medium] we tried to improve all kinds of people’s chances to connect. Bridge, or at least decrease, the geographical distance between people who are trying to realize common objectives.” Quote 3 - Case 2 Scientist

Social media and socialization tactics 
Social media likely increases the strength of linkages. Interviewees that experience superficial - loose and abstract - connections are still likely to yield correct and quick answers, because the role of relational inheritance is limited.

"Relationships between people remain on a superficial level, but that is more an advantage than a disadvantage. Other people will tend to give you the relevant answer more quickly as the bond with you isn’t very complex.” Quote 4 - Key Case 1 Corporate

However, frequently yielding correct and quick answers makes linkages stronger whenever more intense interaction is required.

Bonding - similarity of mind - occurs mainly with others that share an interest in a subject or have a similar opinion. Interviewees perceive social media to increase the chance that new communities develop based on common interests and also increase the speed at which they develop. The latter is very typical for events with a short time horizon as in the following case:

"Relationships and connections created in a [social medium] are extremely useful after the [social medium] is completed. Basically, it creates new communities. This offers huge opportunities. Surely from the company’s perspective, but also for the individuals participating in the [social medium].” Quote 5 - Case 7 - Corporate

Communities take shape as a result of interaction: extending one's usual network and bringing a diverse set of people together based on similarities and complementarities in their respective work. As a result, social media not only increase, but even seem to accelerate bonding compared to conventional media. 
New teams and communities can develop based on a process of natural selection, crossing formal lines of organization. Shaping such communities is centered on content and reciprocity in interaction.

\footnotetext{
"You basically get new teams, that exist as long as there is a give-and-take relationship between members which shapes the process of natural selection for these teams. There is continuous development of teams and there is overlap between teams, all of this happens outside of the formal organization.” Quote 6 - Case 5 - Corporate
}

Word frequency count analysis shows that social media usage aids in getting a feeling for what people think. Whereas this is also typical for e-mail and face-to-face, social media raise the chance of staying updated on others' activities and expertise.

“[...] especially keeping up-to-date with that which other people in your network are doing.” Quote 7 - Case 6 Corporate

Therefore we propose:

Proposition 1a: The use of social media in external knowledge exploration processes results in more transparent and multidirectional interaction and consequently in an increased density of linkages (connectedness), but its impact is moderated by participant role and quality.

Proposition 1b: The use of social media in external knowledge exploration processes results in more transparent interaction and consequently increases the strength of the linkages and bonding between network members (socialization tactics). 


\section{Social media and cross-functional interaction}

The data strongly support social media's ability to enable cross-functional interaction.

Hierarchical lines of authority and lateral boundaries can be surpassed in interaction through social media. Data imply that social media increase an individual's ability to interact across functional boundaries. If face-to-face physical presence is not possible, interaction across functions via social media is the best alternative, because it allows non-temporal and multidirectional interaction. Social media is perceived particularly useful in enabling interaction with various layers of management and knowledgeable experts. Their perspectives, opinions, and positions count. In some cases, management and experts acted as moderators (by linking relevant people to one another based on content and by providing guidance and inspiration). The interest in participating managers and experts stems partially from the perception that they are in a position to impact the decision-making process about innovation.

"It is crucial that you involve those people in groups that know the subject matter well.” Quote 8 - Case 5 - Corporate

“[when asked about management sponsors/hosts:] If he gives positive feedback then you get a proof point that your idea is an interesting one and you can continue on it. Otherwise there is no real point of reference available, and also no real feedback.”

Quote 9 - Key Case 1 - Scientist

Social media communities seem to surpass existing hierarchy in organizations or networks (Quote 10).

\footnotetext{
“I perceive it as open, in this case [of social media usage] you don't have this hierarchy. All those organizational barriers and boundaries, between formal projects and groups, are erased/faded by social media.” Quote 10 - Key Case 1 - Scientist
} 
Participants from the Key Case experience some authority control and hierarchical constraints when it is not entirely transparent whether someone is monitoring the community. However, if this is transparent, they feel free to express their opinions. Most participants express that they do not feel any hierarchical constraints on social media use as well as participating in their communities.

In general, interviewees agree that interaction across functional and hierarchical boundaries creates challenges for management, as there is a shift in the locus of control. However, the additional cases prove that a predesigned strategy can deal with these challenges without limiting the cross-functionality that is unique to social media communities. Social media communities also have self-regulatory abilities: members set their own rules and boundaries (Quote 11).

“[...] we tried our best to build-in certainties that could block any negative aspects. On beforehand, we developed a strategy composed of a number of building blocks: governance, moderation, and escalation. [...] We also found out about social media's unique power, namely its self-regulative ability. It is much less necessary to 'manage' than we had expected, and whenever it is necessary we have our escalation model to intervene with.” Quote 11 - Case 6 - Business

Management is attributed a role: taking away concerns about hierarchical constraint by setting the example, spanning and clarifying boundaries, and thereby providing gateway for employees to participate in (external) social media communities. In the additional cases, managers are deliberately assigned this role and allocated these tasks. Interviewees from the Key Case substantiate that management feedback and general direction-setting alleviate any perceived hierarchical constraint in social media communities (Quote 12). 
Reciprocity - which seems important to cross-functional interaction - was lacking in the Key Case, whilst interviewees expect managers and experts to show dedication to the community by actively giving their insights, opinions, and feedback. It enables them to obtain personal benefits and realize common benefits simultaneously.

Therefore, we propose:

Proposition 2: The use of social media in external knowledge exploration processes results in increased transparency, multi-directionality and, thus, moderation by managers and experts, and in turn, increased cross-functional interaction between network members under the condition of reciprocal behavior.

\section{Social media and receptivity}

Both the interviews and the word frequency count data show evidence of an increase in receptivity - the extent to which more diverse and larger quantities of knowledge can be received through more diverse, and more, receptors - when using social media. First, the reach of participants seems to be extended towards individuals (internally and externally) with different orientations, making it more likely for them to receive multidisciplinary input on discussion issues. Self-regulating groups emerge that build on new ideas from multiple perspectives, in a brainstorm-like fashion, where many individuals and small groups interact (Quote 13).

\footnotetext{
“The [social medium] events broaden people’s perspectives and their reach. [...] You can more easily collect information from a broader spectrum of sources.” Quote 13 - Case 7 - Corporate
} 
In Case 3, sales employees in globally dispersed local markets responded to technology developments put online directly by $R \& D$ employees and vice versa, $R \& D$ employees discussed the local use of products described by sales people. Social media opened up the innovation process; without it these employees did not have access to up-to-date information on technology developments or local market conditions.

Most interviewees express their appreciation for the increased receptiveness to external people (sources of knowledge) and consider this to be beneficial. They are especially receptive to external expert knowledge. One interviewee puts it as an "opportunity to look beyond the borders of the micro system” of which he is part (Key Case 1 - Scientist). However, data also reveal the effect of receptivity only manifests under the conditions that external participants are carefully selected based on role and quality (experience and expertise) and that intellectual property is to some degree protected. If these conditions are not present the discussion remains rather superficial. Interviewees also expressed that they want to be ensured they are allowed to open up to external sources.

\footnotetext{
"Yes, well, to me the internal community is just part of the larger world. So in that sense, having people from the external side also interested in the topic would be nice. But, on the other hand, you also have these barriers with IP protection which are not helping in this way.” Quote 14 - Key Case 1 - Scientist
}

The word frequency count procedure reveals that 'carefulness' and 'stakes' are often recurring words. Interviewees state that there is always a tension between transparency and confidentiality in a business context. With the availability of social media the balance in this tension shifts towards transparency. It seems that participants in the Key Case have difficulty dealing with this tension in the correct way: the uncertainty of impact, possibility of biased information, presence of passive followers, intellectual property protection policy (analysis of policy documents further illustrates its potentially hampering effect), and the stakes involved 
all cause reluctance to exploit the increased transparency social media causes. Though social media do allow for transparency, it is unclear how transparent things are.

Through social media it becomes easier for relevant people to share, further develop, and acquire knowledge (Case 5 - Corporate). Multi-directional interaction results from social media usage. Interviewees from all cases experienced an increased ability to generate knowledge or content on social media, a freedom to participate in social media communities and their beneficial effects. However, some also note that rather than 'true' social and collaborative interaction, various social media platforms today are characterized by large scale individual broadcasting. Then the downsides are overexposed: information pollution, information overload, and one-way communication. To overcome these downsides, it is argued that social media community platforms should be flexible - e.g. using modular designs - in order to allow for adjustments during the community’s existence.

\footnotetext{
"You should develop a flexible model on beforehand, which enables you to deal with all kinds of situations adequately. We have done this with our predesigned building blocks.” Quote 15 - Case 6 - Business
}

Moreover, social media community members are perceived to have access to an increasing amount and variety of external knowledge. The increase in amount of knowledge has both negative and positive sides. One gets a lot of irrelevant information which makes recognition of relevant knowledge more difficult. On the other hand, the amount and variety allow for divergence within a certain knowledge domain. Individuals can get a perception of 'the bigger picture’, composed of knowledge from a variety of perspectives. Word frequency count confirms that social media enable the individual to access varied knowledge in terms of: 'opinions', 'perspectives', 'positions’ of others, 'extremes’, ‘thoughts', and ‘views'. Data suggest that because of increased variety and amount, social media are particularly suitable for exploration and search. 
"It is very nice for diverging; it is a very nice way of doing this. It’s much harder to converge, if you really need something precise and fast, it is usually not the best thing to do it like this. But if you diverge to get, again, width instead of depth...it is much better.” Quote 16 - Key Case 1 - Scientist

Parallel to an increase in amount and variety of knowledge, there is also strong support for increased chances of encountering 'unanticipated knowledge' through social media usage. Word frequency count shows that social media increase the likelihood of 'encountering', 'discovering', 'finding', and 'noticing' all sorts of (sources of) knowledge. One interviewee explained that social media allowed him to make the connection to related but unanticipated knowledge domains much easier.

“[...] through this community we get general insights that lead us to a wholly different understanding of what people want than if we were to link it directly to our products.” Quote 17 - Case 6 - Corporate

Therefore, we propose:

Proposition 3: The use of social media in external knowledge exploration processes results, through transparent and multi-directional interaction, in an increased number of receptors selecting and filtering an increasingly large and varied body of external knowledge (receptivity), if participant selection is carefully based on quality and role, and intellectual property is to some degree protected.

While the role of social media usage is evident in building the capabilities, however, our case studies also show that there are situations in which informants prefer to use other means of communication than social media for purposes such as creating support, assimilating knowledge, and influencing knowledge-related decision-making. Face-to-face contact is 
preferred for rich communication and building trust. Email and Web 1.0 applications are an alternative allowing non-temporal and non-physical communication.

Effects of socialization and coordination capabilities on absorptive capacity The results of our data analysis confirm that not only connectedness, socialization tactics and cross-functionality but also receptivity enhance the absorptive capacity processes of acquisition and assimilation, particularly in the extent of knowledge acquisition support and control. Interestingly, receptivity improved the ability to assimilate external knowledge. However, effective assimilation seems to depend on the activity's goal (divergence) and the person's role (brainstorming). Subjectivity of the available knowledge proved a delicate issue. Some interviewees considered it as a downside, whereas others perceived it as an opportunity to capture the bigger picture on issues.

The cases in our study did not provide any proof yet of whether acquired and assimilated knowledge was transformed and led to actual exploitation of the absorptive capacity. The reason is that the cases studied were still ongoing or had just ended. It is therefore too early to give any indication on the exploitation of the knowledge absorbed.

$====$ Insert Figure 1 about here $===+$

\section{Discussion}

Our exploratory study aimed to understand the organizational mechanisms through which social media usage builds socialization capabilities (connectedness and socialization tactics) and coordination capabilities (cross-functional interaction and receptivity) that in turn develop absorptive capacity processes (Figure 1). 
Our research contributes to the literature on boundary spanning tools and to innovation management research on building absorptive capacity (e.g. Jansen et al., 2005; Spithoven et al., 2011). Our results suggest that social media usage adds transparent, moderational and multidirectional interactions that - under specific conditions - build socialization and coordination capabilities. Such mechanisms and conditions play a role in processes and policies to build and maintain absorptive capacity, that have largely been overlooked (Lane et al., 2006).

Our case study results indicate that transparent interactions are associated not only with increased connectedness (when the participant's role and quality are sufficient) and socialization tactics, but also with cross-functional interaction and receptivity. Transparency not only creates pressure to contribute in social media communities, but also increases the awareness of the value of external knowledge amongst employees, enables easier access to external people and internal people across functions and hierarchies, and stimulates increasing variety in receptors and knowledge. Consequently, it stimulates openness and reduces the reluctance to search for, to incorporate, and to distribute external knowledge and innovations. Moderational interactions by managers and experts are associated with increases in crossfunctional interaction, when moderational interactions are reciprocal. Managers are attributed an important role in facilitating absorptive capacity by synthesizing knowledge by putting it into a business context. This effect complements other research. Managers can structure communication by setting the example and confirming or rejecting directions thereby providing leeway to employees to participate in social media communities (Augier and Teece, 2009) and by gatekeeping and boundary-spanning (Volberda et al., 2010). Moreover, experts in particular play an essential role as they can synthesize knowledge on a content level and can act as boundary spanners by providing connection to relevant external experts. Increased access to expertise is perceived to be one of the key strengths of social media communities. 
Reciprocal interaction is also important for socialization tactics. Although social media appear to have effects on the conditions of absorptive capacity, a general reluctance to participate in social media communities was found. Most prevalent were reservations amongst interviewees to actually opening up to external participants in a multi-directional manner. Reluctance seemed influenced by a fear of losing important knowledge, rather than a sense of the opportunity to more easily capture relevant external knowledge. Such reluctance could be mitigated by reciprocal interaction between participants.

Lastly, multidirectional interactions are associated with increases in connectedness (when the participant's role and quality are sufficient), cross-functional interaction and receptivity (when intellectual property is sufficiently protected). A relatively strict appropriability regime appears to make R\&D staff unconsciously adhere to a strict perspective on appropriability. Individuals impose yet stricter limits on their own behavior than prescribed by the organization, because of the uncertainty they perceive in sharing knowledge through social media. Cohen and Levinthal (1990) find similar effects, but Zahra and George (2002) argue that strong appropriability regimes aid in sustaining competitive advantage. Finding an optimal trade-off between openness and protection seems paramount.

Our study also contributes to the literature on absorptive capacity indicating that receptivity - a hitherto overlooked capability - is positively related to absorptive capacity processes of acquisition and assimilation, where it confirms the positive effects of connectedness, socialization tactics and cross-functional interaction already found in previous research (e.g. Jansen et al., 2005). Receptivity captures knowledge breadth, where factors such as connectedness and cross-functional interaction are associated with common understanding and therefore knowledge depth (Jansen et al., 2005). Knowledge breadth is important in the process of purposefully developing absorptive capacity to explore new knowledge domains whereas knowledge depth is associated with absorptive capacity 
emerging as a byproduct of investments in $R \& D$ that is related to current knowledge domains (Cohen and Levinthal, 1990). In this way companies are more able to pursue an exploration strategy of developing radical new products or obtain a more satisfactory balance between exploration and exploitation (Katila and Ahuja, 2002).

Our study contributes to a better understanding of inbound open innovation. Gassmann (2006) states that new information and communication technologies have reduced the perceived distances between the actors while enabling the integration of customers and suppliers into the design and development process. Our findings show that social media play a powerful role in the integration of other types of external partners and updating relevant knowledge from outside the organization. These findings complement the notion that individual social networks are important in the implementation of open innovation as suggested by Chiaroni et al. (2011).

Limitations and future research implications are the following. Our findings are not generalizable beyond the global high-tech case contexts included in our study. This case study approach allowed an in-depth investigation of firms experimenting with social media that is invaluable to uncover the underlying mechanisms of the proposed relationships and we believe that these findings are comparable for other global high-tech firms. However, future researchers may set up large scale studies in order to test our propositions. Such investigations need not only include other industries and service sectors, but also small and medium-sized firms. These firms are likely to have different social structures with an alternative role of boundary-spanning tools such as social media used for intra-organizational knowledge distribution.

In doing so, future researchers may also want to control for the effects of antecedents of absorptive capacity other than connectedness and cross-functional interaction. Such antecedents may include participation in decision-making (Henderson and Cockburn, 1994), 
attitudes towards change (Murovec and Prodan, 2009), and attitudes towards external technologies (Menon and Pfeffer, 2003). In addition, because our cases permitted us to capture the absorptive capacity of assimilation and acquisition only, future researchers need to include processes of transformation and exploitation.

\section{Management implications}

Companies that aim to benefit from inbound open innovation practices need to create capabilities to assimilate and absorb the input and results. Social media help to build and maintain such capabilities, but only under certain conditions. Shaping these conditions can alleviate the reluctance to participate in social media communities and promote broad exploitation of the conditions created by social media.

Firstly, preconditions created by management can take away some of the uncertainty that appears to underlie the reluctance. Expertise-related antecedents have a similar effect: expert involvement is crucial to benefit from cross-functionality and receptivity. Secondly, when the right intra-organizational arrangements are established, this enhances the conditions created by social media. Social media usage needs to become an accepted part of the firm's communication structure for the proposed relationship to prosper. Lastly, just like in every open innovation initiative, companies need to create a way of working that balances between openness and closeness. With the correct trade-off, an organization can make full use of the capabilities created by social media, whilst ensuring sufficient protection against leakage to realize sustained innovation performance.

From a managerial perspective it is a major challenge not just to acquire and assimilate relevant external knowledge, but to be able to transform the knowledge into commercially viable products, processes and services. Although our research design did not allow us to fully capture the effects of social media usage on the absorptive capacity processes of 
transformation and exploitation, the case studies offer indications that social media may be a valuable social integration mechanism (Easterby-Smith et al., 2008; Todorova and Durisin, 2007; Zahra and George, 2002). In contrast to mechanisms identified in earlier studies, such as knowledge management systems and integrative project teams (Easterby-Smith et al., 2008), social media usage its distinctive advantage might be in its ability to enhance receptivity. In a number of cases, social media enabled interaction between R\&D staff and sales managers or consumers at a scale that is inconceivable when using more conventional social integration mechanisms. Receptivity adds a dimension to social integration mechanisms that may improve the effectiveness of efforts to transform and exploit the knowledge absorbed. 


\section{References}

Aldrich, H. and Herker, D. (1977) Boundary Spanning Roles and Organization Structures. Academy of Management Review, 2, 217-230.

Ashforth, B.K. and Saks, A.M. (1996) Socialization Tactics: Longitudinal Effects on Newcomer Adjustment. Academy of Management Journal, 39, 149-178.

Augier, M. and Teece, D.J. (2009) Dynamic Capabilities and the Role of Managers in Business Strategy and Economic Performance. Organization Science, 20, 410-421.

Bernoff, J. and Li, C. (2008) Harnessing the Power of the Oh-So-Social Web. MIT Sloan Management Review, 49, 36-42.

Boschma, R.A. (2005) Proximity and Innovation: A Critical Assessment. Regional Studies, 39, 61-74. Chesbrough, H. (2006) Open Innovation: A New Paradigm for Understanding Industrial Innovation, In H. Chesbrough, W. Vanhaverbeke, and J. West (Eds.), Open Innovation: Researching a New Paradigm, Oxford university press, Oxford, 1-14.

Chiaroni, D., Chiesa, V., and Frattini, F. (2011) The Open Innovation Journey: How Firms Dynamically Implement the Emerging Innovation Management Paradigm. Technovation, 31, 34-43. Cohen, W.M. and Levinthal, D.A. (1990) Absorptive Capacity: A New Perspective on Learning and Innovation. Administrative Science Quarterly, 35, 128-152.

Dyer, J.H. and Singh, H. (1998) The Relational View: Cooperative Strategy and Sources of Interorganizational Competitive Advantage. Academy of management review, 23, 660-679.

Easterby-Smith, M., Graça, M., Antonacopoulou, E., and Ferdinand, J. (2008) Absorptive Capacity: A Process Perspective. Management Learning, 39, 483-501.

Ebers, M. and Maurer, I. (2014) Connections Count: How Relational Embeddedness and Relational Empowerment Foster Absorptive Capacity. Research Policy, 43, 318-332.

Egelhoff, W.G. (1991) Information-Processing Theory and the Multinational-Enterprise. Journal of International Business Studies, 22, 341-368.

Eisenhardt, K.M. (1989) Building Theories from Case Study Research. Academy of Management Review, 14, 532-550.

Fabrizio, K.R. (2009) Absorptive Capacity and the Search for Innovation. Research Policy, 38, 255267.

Flick, U. (2009) An Introduction to Qualitative Research (4 ed.), Sage Publications Ltd, London. Galbraith, J.R. (1973) Designing Complex Organizations, Addison-Wesley Longman Publishing Co., Inc., Reading, MA.

Galunic, D.C. and Rodan, S. (1998) Resource Recombinations in the Firm: Knowledge Structures and the Potential for Schumpeterian Innovation. Strategic Management Journal, 19, 1193-1201.

Gassmann, O. (2006) Opening up the Innovation Process: Towards an Agenda. R\&D Management, 36, $223-228$.

Gibbert, M., Ruigrok, W., and Wicki, B. (2008) What Passes as a Rigorous Case Study? Strategic Management Journal, 29, 1465-1474.

Grabher, G. and Stark, D. (1997) Organizing Diversity: Evolutionary Theory, Network Analysis and Postsocialism. Regional Studies, 31, 533-544.

Granovetter, M.S. (1992) Problems of Explanation in Economic Sociology, In N. Nohria, and R. Eccles (Eds.), Networks and Organizations: Structure, Form and Action, Harvard Business School Press, Boston.

Hage, J. and Aiken, M. (1967) Program Change and Organizational Properties - Comparative Analysis. American Journal of Sociology, 72, 503-519.

Henderson, R. and Cockburn, I. (1994) Measuring Competence? Exploring Firm Effects in Pharmaceutical Research. Strategic Management Journal, 15, 63-84.

Huizingh, E.K.R.E. (2011) Open Innovation: State of the Art and Future Perspectives. Technovation, 31, 2-9.

Jansen, J.J.P., Van den Bosch, F.A.J., and Volberda, H.W. (2005) Managing Potential and Realized Absorptive Capacity: How Do Organizational Antecedent's Matter? Academy of Management Journal, 48, 999-1015.

Jaworski, B.J. and Kohli, A.K. (1993) Market Orientation: Antecedents and Consequences. Journal of Marketing, 57, 53-70. 
Jiménez-Barrionuevo, M.M., García-Morales, V.J., and Molina, L.M. (2011) Validation of an Instrument to Measure Absorptive Capacity. Technovation, 31, 190-202.

Kafouros, M.I. (2006) The Impact of the Internet on R\&D Efficiency: Theory and Evidence. Technovation, 26, 827-835.

Kaplan, A.M. and Haenlein, M. (2010) Users of the World, Unite! The Challenges and Opportunities of Social Media. Business Horizons, 53, 59-68.

Katila, R. and Ahuja, G. (2002) Something Old, Something New: A Longitudinal Study of Search Behavior and New Product Introduction. Academy of Management Journal, 45, 1183-1194.

Kijkuit, B. and van den Ende, J. (2010) With a Little Help from Our Colleagues: A Longitudinal Study of Social Networks for Innovation. Organization Studies, 31, 451-479.

Lane, P.J., Koka, B.R., and Pathak, S. (2006) The Reification of Absorptive Capacity: A Critical Review and Rejuvenation of the Construct. Academy of Management Review, 31, 833-863.

Lane, P.J. and Lubatkin, M. (1998) Relative Absorptive Capacity and Interorganizational Learning. Strategic Management Journal, 19, 461-477.

Lazaric, N., Longhi, C., and Thomas, C. (2008) Gatekeepers of Knowledge Versus Platforms of Knowledge: From Potential to Realized Absorptive Capacity. Regional Studies, 42, 837-852. Lewin, A.Y., Massini, S., and Peeters, C. (2011) Microfoundations of Internal and External Absorptive Capacity Routines. Organization Science, 22, 81-98.

Malmberg, A. and Maskell, P. (1997) Towards an Explanation of Regional Specialization and Industry Agglomeration. European planning studies, 5, 25-41.

Marabelli, M. and Newell, S. (2014) Knowing, Power and Materiality: A Critical Review and Reconceptualization of Absorptive Capacity. International Journal of Management Reviews. March, J.G. (1991) Exploration and Exploitation in Organizational Learning. Organization Science, 2, 71-87.

Menon, T. and Pfeffer, J. (2003) Valuing Internal Vs. External Knowledge: Explaining the Preference for Outsiders. Management Science, 49, 497-513.

Michelis, D. and Schildhauer, T. (2010) Social Media Handbuch: Theorien, Methoden, Modelle, Nomos Verlagsgesellschaft / Edition Reinhard Fischer, Baden-Baden.

Murovec, N. and Prodan, I. (2009) Absorptive Capacity, Its Determinants, and Influence on Innovation Output: Cross-Cultural Validation of the Structural Model. Technovation, 29, 859-872. Nahapiet, J. and Ghoshal, S. (1998) Social Capital, Intellectual Capital, and the Organizational Advantage. Academy of management review, 23, 242-266.

Pinto, M.B. and Pinto, J.K. (1990) Project Team Communication and Cross-Functional Cooperation in New Program Development. Journal of Product Innovation Management, 7, 200-212.

Prabhu, J.C., Chandy, R.K., and Ellis, M.E. (2005) The Impact of Acquisitions on Innovation: Poison Pill, Placebo, or Tonic? Journal of Marketing, 69, 114-130.

Rindfleisch, A. and Moorman, C. (2001) The Acquisition and Utilization of Information in New Product Alliances: A Strength-of-Ties Perspective. Journal of marketing, 65, 1-18.

Rowley, T., Behrens, D., and Krackhardt, D. (2000) Redundant Governance Structures: An Analysis of Structural and Relational Embeddedness in the Steel and Semiconductor Industries. Strategic Management Journal, 21, 369-386.

Spithoven, A., Clarysse, B., and Knockaert, M. (2011) Building Absorptive Capacity to Organise Inbound Open Innovation in Traditional Industries. Technovation, 30, 130-141.

Tether, B.S. (2002) Who Co-Operates for Innovation, and Why - an Empirical Analysis. Research Policy, 31, 947-967.

Todorova, G. and Durisin, B. (2007) Absorptive Capacity: Valuing a Reconceptualization. Academy of Management Review, 32, 774-786.

Tsai, W.P. (2001) Knowledge Transfer in Intraorganizational Networks: Effects of Network Position and Absorptive Capacity on Business Unit Innovation and Performance. Academy of Management Journal, 44, 996-1004.

Uzzi, B. (1997) Social Structure and Competition in Interfirm Networks: The Paradox of

Embeddedness. Administrative science quarterly, 35-67.

Van Bruggen, G.H., Lilien, G.L., and Kacker, M. (2002) Informants in Organizational Marketing Research: Why Use Multiple Informants and How to Aggregate Responses. Journal of Marketing Research, 39, 469-478. 
van de Vrande, V., Vanhaverbeke, W., and Duysters, G. (2011) Technology in-Sourcing and the Creation of Pioneering Technologies. Journal of Product Innovation Management, 28, 974-987. Van Den Bosch, F.A., Volberda, H.W., and De Boer, M. (1999) Coevolution of Firm Absorptive Capacity and Knowledge Environment: Organizational Forms and Combinative Capabilities. Organization Science, 10, 551-568.

Verona, G. (1999) A Resource-Based View of Product Development. Academy of Management Review, 24, 132-142.

Volberda, H.W., Foss, N.J., and Lyles, M.A. (2010) Absorbing the Concept of Absorptive Capacity: How to Realize Its Potential in the Organization Field. Organization Science, 21, 931-951.

Yin, R.K. (2009) Case Study Research: Design and Methods (4 ed.), Sage Publications, London. Zahra, S.A. and George, G. (2002) Absorptive Capacity: A Review, Reconceptualization, and Extension. Academy of Management Review, 27, 185-203. 
Table 1 Contexts, interviews and roles of interviewees per case

\begin{tabular}{|c|c|c|c|c|c|c|c|c|}
\hline \multirow[t]{2}{*}{ Case } & \multirow[t]{2}{*}{ Context } & \multirow[t]{2}{*}{ Role in innovation process } & \multirow[t]{2}{*}{ Social media } & \multirow[t]{2}{*}{ Interviews } & \multicolumn{4}{|c|}{ Interviewee roles } \\
\hline & & & & & Scientists & Expert & Corporate & Business \\
\hline 1 (Key Case) & $\mathrm{R} \& \mathrm{D}$ & Knowledge exploration & SocialCast & 20 & 17 & 1 & 1 & 1 \\
\hline 2 & $\mathrm{R} \& \mathrm{D}$ & Idea generation & Dedicated & 3 & 2 & & 1 & \\
\hline 3 & $\mathrm{R} \& \mathrm{D}$ & Connecting R\&D and Business & Dedicated & 2 & & & 2 & \\
\hline 4 & $\mathrm{R} \& \mathrm{D}$ & Sourcing external ideas & Dedicated & 1 & & & & 1 \\
\hline 5 & $\mathrm{R} \& \mathrm{D}$ & Connecting R\&D and Suppliers & Dedicated & 1 & & & 1 & \\
\hline 6 & Business & Knowledge exploration among users & LinkedIn & 3 & & & 1 & 2 \\
\hline 7 & Business & Idea generation & Dedicated & 2 & & & 2 & \\
\hline
\end{tabular}


Figure 1 Conceptual model based on empirical results

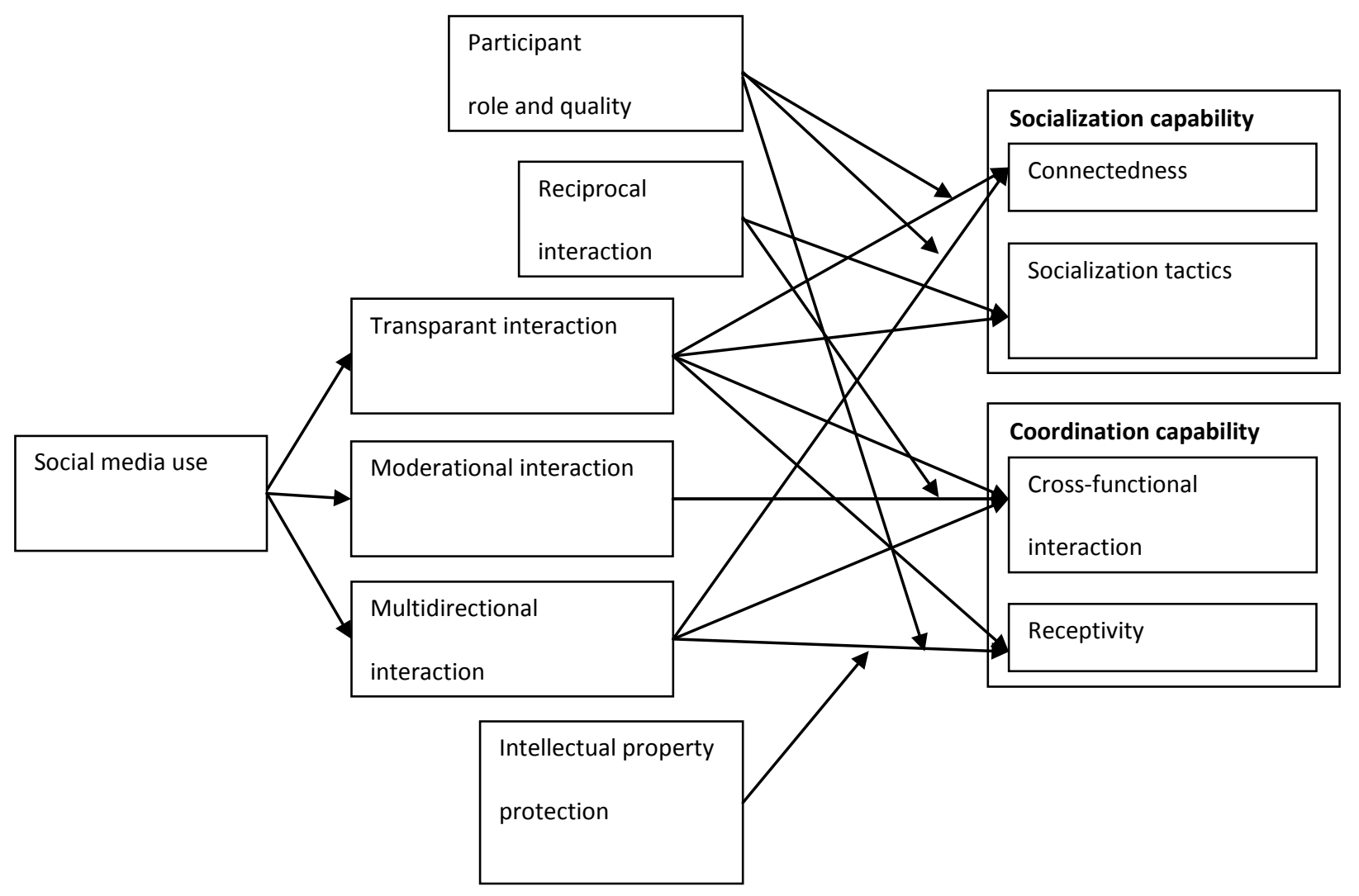

Note: All relationships are positive. 